\title{
Overweight and obesity in association with factors related to breastfeeding in Arar, Northern Saudi Arabia
}

\author{
Ohud Falah M Alanazi ${ }^{1}$, Sawsan Hassan Abdullah Hashim ${ }^{2}$, Nagah Mohamed Abo El-Fetoh ${ }^{3}$, Manal \\ Hajea Eid Alenazy ${ }^{1}$, Ayashah Moulfi A Alhazmi ${ }^{1}$, Reham Aref Alenezi ${ }^{1}$, Ibtisam Matan Alanazi ${ }^{1}$, Fai \\ Mulfi S Alanzi ${ }^{1}$, Raghad Khalid R Alruwaili ${ }^{1}$, Ahlam Sultan Alanazi ${ }^{1}$, Aliah Saad M Alruwaili ${ }^{1}$, Noof \\ Saad M Alruwaili ${ }^{1}$ \\ ${ }^{1}$ Faculty of Medicine, Northern Border University, ${ }^{2}$ Paediatrics department, Faculty of Medicine, Northern Border \\ University, Arar, KSA. ${ }^{3}$ Associate Prof. of Public Health and Community Medicine, Faculty of Medicine, Sohag \\ University, Egypt
}

\begin{abstract}
Background: There is evidence that breastfeeding (BF) may have protective effect against obesity. In some studies, a time-dependent association between duration of BF and obesity has also been shown.

Objectives: This community-based study was conducted aimed to evaluate the prevalence of overweight and obesity in children 2-12 years in association with factors related to breastfeeding in Arar City, Northern Saudi Arabia.

Participants and methods: A cross-sectional study was carried out in Arar City, mothers were selected from the attendees of the female side of 5 randomly selected primary health care centres in the city. They were interviewed and filled a questionnaire which included the needed questions.

Results: Among the 562 studied children, 54.8\% were females and the estimated proportion of obese and overweight children are $39.9 \%$ and $13.9 \%$, respectively. The BMI group proportions were significantly affected by the period of breastfeeding, father's obesity, and type of feeding; whether it was artificial or breastfeeding, or both $(\mathrm{P}<0.05)$. We found that $43 \%$ of those who were underfed; breastfed for less than 4 months only, were obese and $8.8 \%$ were overweight. Among those who were breast-fed for 4 to 6 months, $31.2 \%$ were obese and $20.8 \%$ were overweight and for those that had a 6 months to a year breastfeeding, $19.4 \%$ and $12.9 \%$ were obese and overweight, respectively.

Conclusion: In Arar City, Northern Saudi Arabia, the BMI of children 2-12 years is significantly affected by the period of breastfeeding, father's obesity, and type of feeding; whether it is artificial or breast-feeding, or both $(\mathrm{P}<0.05)$. So policy makers must condense their efforts to increase the awareness of the mothers about the protective effect of breastfeeding from obesity and its comorbidities.
\end{abstract}

Key words: Breastfeeding, Childhood, Artificial feeding, BMI, Obesity, Arar City, Northern Saudi Arabia.

\section{INTRODUCTION}

Prevalence of childhood obesity has increased markedly worldwide in the last three decades and become a major public health crisis around the world ${ }^{[1]}$. Since obesity and overweight are correlated with life-threatening diseases including diabetes, high cholesterol levels, hypertension, cardiovascular diseases, stroke, and certain types of cancers, the number of deaths related to obesity is estimated at 2.8 million per year ${ }^{[2]}$. There is evidence that breastfeeding may have protective effect against obesity ${ }^{[3]}$. In some studies, a time-dependent association between duration of BF and obesity has also been shown ${ }^{[4]}$.The link between childhood obesity and breastfeeding can be explained that breast milk contains less calories and nutrients as well as bioactive substances, including leptin and ghrelin. However, the higher protein and fat levels in formula milk have been associated with higher adiposity levels ${ }^{[5]}$. Some research attributed the association to higher levels of insulin hormone and a longer response to insulin in formulae-fed infants than the breastfed ones. This increases the fat storage when high protein is present ${ }^{[6,7]}$.

In a study conducted to examine the relationship between breastfeeding (BF) and odds of childhood obesity in Hispanic children, it was reported that, infants exclusively formula fed at birth were significantly more likely than fully breastfed infants to be obese at early childhood ( $\mathrm{P}<0.001)$. For every additional month of any BF, obesity risk at early childhood decreased by $1 \%$. Every additional month of full BF conferred a 3\% decrease in obesity risk ${ }^{[8]}$.

Another study was conducted in Iran to investigate the weight status and its relationship to infant-feeding and BMI in Iranian children, it was concluded that total time of $\mathrm{BF}$ and duration of exclusive BF were not associated with childhood BMI and the timing of introduction of complementary feeding was inversely related to childhood BMI. Children with an early introduction of complementary feeding had significantly higher mean BMI ${ }^{[9]}$. 
The surveillance of obesity among children over time requires studies and prevalence data. Malnutrition in infancy and childhood may result in both short and long term irreversible negative health outcomes and thus studies are run to point out the factors that can affect the growth of children, make recommendations for the governmental programs and health-care system in addition to the effective interventions of the parents.

This community-based study was conducted aimed to evaluate the prevalence of overweight and obesity in association with factors related to breastfeeding.

\section{SUBJECTS AND METHODS}

\section{Study type and period:}

This cross-sectional community-based study was conducted on 562 children of both sexes, aged 2-12 years during the period from $1^{\text {st }}$ October, 2017 to $30^{\text {th }}$ April 2018.

The formula $n=z 2 p(1-p) / e 2$ was used to estimate the sample size. Considering the prevalence of stunted growth in Arar is 50\%, target population more than 1000 , study power $95 \%$, absolute error 5\%, and a nonresponse rate $20 \%$.

Mothers were selected from the attendees of the female side of 5 randomly selected primary health care centers in the city using systematic random sampling technique (every $3^{\text {rd }}$ mother). They were interviewed and filled a questionnaire which include the needed questions about their children under 12 years old.

The questionnaire included questions about socio-demographic characteristics of the participants, including age, sex, child order between siblings, average family income per month and parents' education, work and consanguinity. In addition, the questionnaire included inquiries about type of the child feeding (breastfeeding or artificial feeding or both), period of breastfeeding, exclusive breastfeeding, presence of chronic diseases, comorbidities and some feeding related parameters of the studied children.

Child bodyweight and height was obtained to calculate the BMI. Body mass index (BMI) was calculated as per the formula BMI $=$ weight $(\mathrm{kg}) /$ height $\left(\mathrm{m}^{2}\right)$. Study subjects were classified as underweight $(\mathrm{BMI}<18.5)$, normal weight BMI from18.5 to 25), overweight (BMI from 25.01 to 30 ), and obese (BMI>30).

\section{Statistical analysis:}

Data were compiled and analyzed using statistical package for the social sciences (SPSS, version 16) and results were analyzed with frequencies and Chi-squared test as appropriate. Pvalue was considered significant if $<0.05$.

\section{Ethical consideration:}

Mothers were informed that participation is completely voluntary. No names were recorded on the questionnaires. All questionnaires were kept safe.

\section{RESULTS}

Table (1) shows the socio-demographic characteristics and BMI group of the studied children. It revealed that, studied children were $562,54.8 \%$ were females, $20.6 \%$ 8-10 years and about third $31.7 \%$ aged $10-12$ years. Parental higher education (university or more) was $71.2 \%$ among mothers and $62.6 \%$ among fathers. However, $44 \%$ of mothers were housewives. The estimated proportion of obese and overweight children are $39.9 \%$ and $13.9 \%$, respectively.

Table (2) illustrates the breastfeeding related variables among the studied children. Among those children, $40.6 \%$ were breastfed for less than 4 months and $40.9 \%$ had absolute breastfeeding in the first 6 months after birth, 52.3\% had both breast and artificial feeding. It was also found that the children who were never breastfed (artificial feeding) were $33.5 \%$. The majority suffered no chronic nor hereditary diseases.

Table (3) shows the relationship between the child's BMI and breastfeeding related variables among the studied children. The BMI group proportions were significantly affected by the period of breastfeeding, father's obesity, and type of feeding; whether it is artificial or breast-feeding, or both $(\mathrm{P}<0.05)$.

We found that $43 \%$ of those who were underfed; breastfed for less than 4 months only, were obese and $8.8 \%$ were overweight. Among those who were breast-fed for 4 to 6 months, $31.2 \%$ were obese and $20.8 \%$ were overweight and for those that had a 6 months to a year breastfeeding, $19.4 \%$ and $12.9 \%$ were obese and overweight, respectively. The ration seems to be decreasing in an indirect proportional relationship between time of breastfeeding and BMI. However, 
Overweight and obesity in association with factors related to breastfeeding ....

the obesity prevalence increased markedly with further increase in the period of breastfeeding for more than one year; as $55.3 \%$ and $10.5 \%$ among those who were breastfed for 12 to 18 months were obese and overweight, respectively, and $42 \%$ and $22 \%$ were obese and overweight, respectively, among those who had more than 18-months period of breastfeeding.

Table (1): Socio-demographic characteristics and BMI group of the studied children, Arar, 2018 $(\mathrm{N}=562)$.

\begin{tabular}{|c|c|c|}
\hline & No. & Percent \\
\hline \multicolumn{3}{|l|}{ Age group } \\
\hline $2-4$ & 116 & 20.6 \\
\hline $4-6$ & 60 & 10.7 \\
\hline $6-8$ & 92 & 16.4 \\
\hline $8-10$ & 116 & 20.6 \\
\hline $10-12$ & 178 & 31.7 \\
\hline \multicolumn{3}{|l|}{ Sex } \\
\hline Female & 308 & 54.8 \\
\hline Male & 254 & 45.2 \\
\hline \multicolumn{3}{|l|}{ Mothers' education } \\
\hline Illiterate & 10 & 1.8 \\
\hline Primary & 14 & 2.5 \\
\hline Read and write & 20 & 3.6 \\
\hline Secondary & 94 & 16.7 \\
\hline University or more & 400 & 71.2 \\
\hline Preparatory & 24 & 4.3 \\
\hline \multicolumn{3}{|l|}{ Fathers' education } \\
\hline Illiterate & 4 & .7 \\
\hline Primary & 12 & 2.1 \\
\hline Read and write & 14 & 2.5 \\
\hline Secondary & 138 & 24.6 \\
\hline University or more & 352 & 62.6 \\
\hline Preparatory & 42 & 7.5 \\
\hline \multicolumn{3}{|l|}{ Mothers' work } \\
\hline Working & 315 & 56.0 \\
\hline House wife & 247 & 44.0 \\
\hline \multicolumn{3}{|l|}{ Average family income } \\
\hline$>15000$ & 240 & 42.7 \\
\hline$<2000$ & 28 & 5.0 \\
\hline $10000-14000$ & 120 & 21.4 \\
\hline $2000-5000$ & 42 & 7.5 \\
\hline $5000-10000$ & 132 & 23.5 \\
\hline \multicolumn{3}{|l|}{$\begin{array}{l}\text { Consanguinity between } \\
\text { parents }\end{array}$} \\
\hline Cousins & 178 & 31.7 \\
\hline No relation & 302 & 53.7 \\
\hline Of the same family & 82 & 14.6 \\
\hline \multicolumn{3}{|c|}{$\begin{array}{l}\text { Child order among his/her } \\
\text { siblings }\end{array}$} \\
\hline $1 \mathrm{st}$ & 122 & 21.8 \\
\hline 3 rd & 68 & 12.1 \\
\hline 2 nd & 102 & 18.1 \\
\hline 4th or more & 270 & 48.0 \\
\hline \multicolumn{3}{|l|}{ BMI group } \\
\hline Underweight & 134 & 23.8 \\
\hline Normal & 126 & 22.4 \\
\hline Overweight & 78 & 13.9 \\
\hline Obese & 224 & 39.9 \\
\hline
\end{tabular}

Table (2): Breastfeeding related variables among the studied children.

\begin{tabular}{|l|c|c|}
\hline & No. & \% \\
\hline Type of infant feeding & & \\
\hline Both & 294 & 52.3 \\
\hline Artificial feeding & 188 & 33.5 \\
\hline Breastfeeding & 80 & 14.2 \\
\hline Period of breastfeeding (in months) & & \\
\hline$<4$ & 228 & 40.6 \\
\hline $4-6$ & 96 & 17.1 \\
\hline $6-12$ & 62 & 11.0 \\
\hline $12-18$ & 76 & 13.5 \\
\hline$>18$ & 100 & 17.8 \\
\hline Absolute breastfeeding in the 1st 6 months of life & & \\
\hline Yes & 230 & 40.9 \\
\hline No & 332 & 59.1 \\
\hline Chronic diseases & & \\
\hline Bronchial asthma & 14 & 2.5 \\
\hline Skin allergy & 2 & .4 \\
\hline liver cell failure & 2 & .4 \\
\hline Chronic anemia & 2 & .4 \\
\hline Others & 8 & 1.4 \\
\hline No chronic diseases & 534 & 95.0 \\
\hline Hereditary disease & & \\
\hline No & 538 & 95.7 \\
\hline Yes & 24 & 4.3 \\
\hline Mothers' Obesity & & \\
\hline No & 402 & 71.5 \\
\hline Yes & 160 & 28.5 \\
\hline
\end{tabular}

Table (3): Relationship between the child's BMI and breastfeeding related variables among the studied children

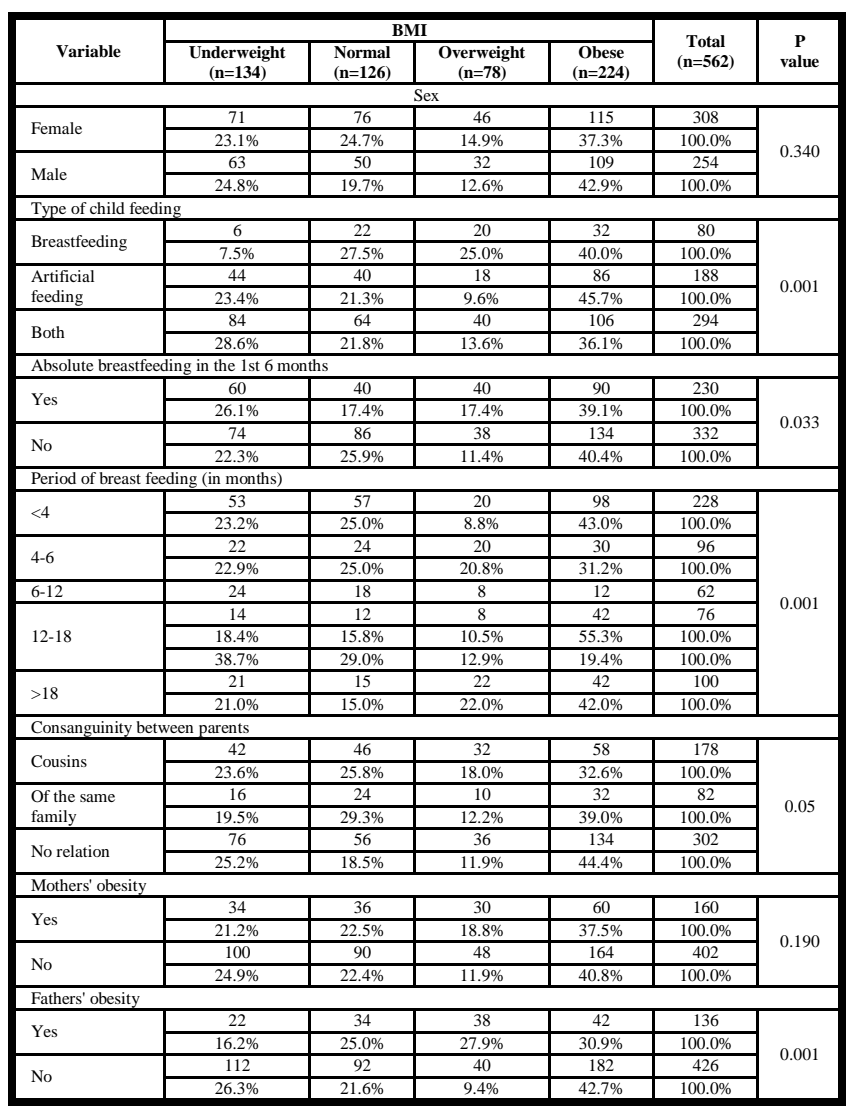




\section{DISCUSSION}

The link between childhood obesity and breastfeeding can be explained that breast milk contains less calories and nutrients as well as bioactive substances, including leptin and ghrelin. However, the higher protein and fat levels in formula milk have been associated with higher adiposity levels ${ }^{[5]}$.

This cross-sectional community-based study was conducted on 562 children of both sexes, aged 2-12 years during the period from $1^{\text {st }}$ October, 2017 to $30^{\text {th }}$ April 2018 to evaluate the prevalence of overweight and obesity in association with factors related to breastfeeding.

The study revealed that, the BMI group proportions are significantly affected by the period of breastfeeding, father's obesity, and type of feeding; whether it is artificial or breast-feeding, or both $(\mathrm{P}<0.05)$. Among those children, $40.6 \%$ were breastfed for less than 4 months and $40.9 \%$ had absolute breastfeeding in the first 6 months after birth. The majority suffered no chronic nor hereditary diseases.

We found that $43 \%$ of those who were underfed; breastfed for less than 4 months only, were obese and $8.8 \%$ were overweight. Among those who were breast-fed for 4 to 6 months, $31.2 \%$ were obese and $20.8 \%$ were overweight and for those that had a 6 months to a year breastfeeding, $19.4 \%$ and $12.9 \%$ were obese and overweight, respectively.

The ration seems to be decreasing in an indirect proportional relationship between time of breastfeeding and BMI. However, the obesity prevalence increased markedly with further increase in the period of breastfeeding for more than one year; as $55.3 \%$ and $10.5 \%$ among those who were breastfed for 12 to 18 months were obese and overweight, respectively, and $42 \%$ and $22 \%$ were obese and overweight, respectively, among those who had more than 18-months period of breastfeeding.

It was reported by Kersey et al. ${ }^{[10]}$ that increased duration of breastfeeding in the first year of life was significantly associated with a decrease in the risk of overweight among pre-schoolers, so that each additional month of breastfeeding was associated with a $10 \%$ decreased of overweight after controlling the sample for child's sex, birth weight group, current age, prematurity, maternal weight status and maternal education level. McCrory and Layte ${ }^{[11]}$ found among 7798 Ireland school-going children aged 9 years old that breastfeeding for between 13 and 25 weeks was associated with a $38 \%$ reduction in the risk of increased BMI, while being breastfed in excess of 26 weeks was associated with a $51 \%$ reduction in risk of increased BMI. No significant association was found between obesity and the children breastfed for less than 26 weeks ${ }^{[11]}$.

Our study also found that the children who were never breastfed were $33.5 \%$. This percentage is much higher than that of Hassan et al. ${ }^{[12]}$ which found the corresponding percentage to be $12.8 \%$ among Egyptian children. The majority (45.7\%) of the artificially-fed children were obese and $9.6 \%$ of them are overweight. In the study of Vafa et al. ${ }^{[9]}$ run in Tehran, Iran, it was found that $25.8 \%$ of the both breastmilk- and formulae-fed children were overweight ${ }^{[10]}$.

The study of Alanazi et al. ${ }^{[13]}$, which assessed the BMI and underweight status in adolescents the same area as our study, Arar, KSA, found that only $2.7 \%$ of the participants ages 12-15 were obese and found a deviation towards underweight in comparison to international standards and findings. The total prevalence of obese children in our study is $39.9 \%$, which is markedly higher than the findings of Alanazi et al. ${ }^{[13]}$. A marked association was found between the children obesity and fathers' obesity $(\mathrm{P}=0.001)$, while no significant association was found between children and mothers' obesity $(\mathrm{P}=0.109$ ). Among the $40.6 \%$ that had absolute breastfeeding in the first 6 months, 39.1\% were found to be obese and the relationship is insignificant $(\mathrm{P}=0.125)$. Consanguinity between parents, and sex of child were also found to be insignificant $(\mathrm{P}=0.091$, and 0.337 , respectively).

\section{CONCLUSION AND RECOMMENDATIONS}

In Arar city, Northern Saudi Arabia, the BMI of children 2-12 years is significantly affected by the period of breastfeeding, father's obesity, and type of feeding; whether it is artificial or breast-feeding, or both $(\mathrm{P}<0.05)$. So policy makers must condense their efforts to increase the awareness of the mothers about the protective effect of breastfeeding from obesity and its comorbidities.

\section{ACKNOWLEDGEMENT}

The success and final outcome of this research paper required assistance from many people for completion of this work. Our thanks go to Dr. 
Zeinab Mohammad Ibrahim (Assistant professor of pediatrics, Faculty of Medicine, Northern Border University, Arar, KSA), Afrah Saleh K Alanazi (Faculty of Medicine, Northern Border University, Arar, KSA) Abdalla Mohamed Bakr Ali (Medical Student, Sohag University, Egypt), for their help in different steps of the research.

\section{REFERENCES}

1. Wang Y, Lobstein T (2006): Worldwide trends in childhood obesity. Int J Pediatr Obes., 1:11-25.

2. Ranjani H, Mehreen T, Pradeepa $\mathrm{R}$ et al. (2016): Epidemiology of childhood overweight $\&$ obesity in India: A systematic review. Indian J Med Res., 143(2): 160-174.

3. Lamb M, Dabelea D, Yin X et al. (2010): Early life predictors of higher body mass index in healthy children. Ann Nutr Metab., 56:16-22.

4. Harder T, Bergmann R, Kallischnigg G et al. (2010): Duration of breastfeeding and risk of overweight: a meta-analysis. Am J Epidemiol., 162:397-403.

5. Yan J, Liu L, Zhu Y et al. (2014): The association between breast feeding and childhood obesity: A meta analysis. BMC Public Health, 14 : 1267.

6. Wang L, Collins C, Ratliff M et al. (2017): Breastfeeding reduces childhood obesity risks. Child Obes., 13 : 197-204.

7. Hediger M, Overpeck M, Kuczmarski R et al. (2001): Association between infant breastfeeding and overweight in young children. JAMA., 285(19):2453-60.

8. Shannon E, Koleilat M, Leonard S et al. (2017): Breastfeeding Is Associated With Reduced Obesity in Hispanic 2- to 5-Year-Olds Served by WIC. Journal of Nutrition Education and Behaviour, 49(7):S144-S150.

9. Vafa M, Moslehi N, Afshari S et al. (2012): Relationship between Breastfeeding and Obesity in Childhood. Journal of Health, Population, and Nutrition, 30(3):303-310.

10. Kersey M, Lipton R, Sanchez-Rosado M et al. (2005): Breastfeeding history and overweight in Latino preschoolers. Ambul Pediatr., 5:355-358.

11. McCrory $C$ and Layte $R$ (2012): Breastfeeding and risk of overweight and obesity at nine-years of age. Soc Sci Med Soc Sci Med., 75(Jul):323-330.
12. Hassan N, El-Masry S, El-Batrawy S et al. (2017): Relationship between breast feeding duration and risk of overweight/obesity among Egyptian children. Egyptian Pediatric Association Gazette, 66(1):9-14.

13. Alanazi AM, Ali AM, Ory ZM et al. (2018): Underweight Adolescents in Northern Saudi Arabia: A Community Based Study. The Egyptian Journal of Hospital Medicine, 71(7):3641-47. 